\title{
Regulation of interferon gamma signaling by suppressors of cytokine signaling and regulatory $T$ cells
}

\section{Joseph Larkin III *, Chulbul M. Ahmed, Tenisha D. Wilson and Howard M. Johnson}

Department of Microbiology and Cell Science, University of Florida, Gainesville, FL, USA

\section{Edited by:}

Kendall A. Smith, Weill Cornell

Medical College of Cornell University, USA

\section{Reviewed by:}

Bruno Lucas, Centre National de la Recherche Scientifique, France

Mauricio Martins Rodrigues, Federal University of São Paulo, Brazil

\section{*Correspondence:}

Joseph Larkin III, Department of

Microbiology and Cell Science,

University of Florida, PO Box 110700

Museum Road Building 981,

Gainesville, FL 32611, USA

e-mail: jlarkin3@ufl.edu
Regulatory T cells (Tregs) play an indispensable role in the prevention of autoimmune disease, as interferon gamma (IFN $\gamma$ ) mediated, lethal auto-immunity occurs (in both mice and humans) in their absence. In addition, Tregs have been implicated in preventing the onset of autoimmune and auto-inflammatory conditions associated with aberrant IFN $\gamma$ signaling such as type 1 diabetes, lupus, and lipopolysaccharide (LPS) mediated endotoxemia. Notably, suppressor of cytokine signaling-1 deficient (SOCS1-/-) mice also succumb to a lethal auto-inflammatory disease, dominated by excessive IFN $\gamma$ signaling and bearing similar disease course kinetics to Treg deficient mice. Moreover SOCS1 deficiency has been implicated in lupus progression, and increased susceptibility to LPS mediated endotoxemia. Although it has been established that Tregs and SOCS1 play a critical role in the regulation of IFN $\gamma$ signaling, and the prevention of lethal auto-inflammatory disease, the role of Treg/SOCS1 cross-talk in the regulation of IFN $\gamma$ signaling has been essentially unexplored. This is especially pertinent as recent publications have implicated a role of SOCS1 in the stability of peripheral Tregs. This review will examine the emerging research findings implicating a critical role of the intersection of the SOCS1 and Treg regulatory pathways in the control of IFN gamma signaling and immune system function.

Keywords: auto-immunity, T cells, tolerance/suppression/anergy, inflammation, lupus

\section{INTRODUCTION}

The primary role of the immune system is to eliminate pathogenic, infectious agents and altered self (cancers) (1-3). Interferon gamma (IFN $\gamma)$ plays a critical role in the capacity of the immune system to recognize and eliminate pathogenic agents through increased presentation of antigens by antigen presenting cells, induction of an anti-viral state in infected cells, and mediation of anti-microbial effector functions (4). In addition, IFN $\gamma$ serves to mediate the destruction of cancerous cells by inducing an anti-proliferative state, enhancing NK cell activity, and mediating antibody production (4-6). Conversely, aberrant immune system functions can result in the destruction of self-tissues (autoimmunity) and dysbiosis of natural gut flora communities $(1,7)$. It is therefore essential that IFN $\gamma$, a central effector of the immune system, be carefully regulated. Foxp $3^{+}$regulatory T cells (Tregs), and the intracellular protein suppressor of cytokine signaling-1 (SOCS1), are two critical regulators of IFN $\gamma$ signaling. In this review we will: (1) define the role of these two mechanisms in the regulation of IFN $\gamma$ signaling, (2) examine evidence suggesting cross-talk between these two pathways, and (3) explore emerging research whereby IFN $\gamma$ signaling is regulated through the use of SOCS1 mimetic peptides.

\section{IFN GAMMA SIGNALING}

The sole type II interferon, IFN $\gamma$ is a multipotent cytokine secreted by activated $\mathrm{T}$ cells and natural killer cells and is responsible for the modulation of many facets of immune response. IFN $\gamma$ exerts its effects through interactions with the IFN $\gamma$ receptor complex (IFNGR) on the surface of target cells. The IFNGR is a heterodimeric complex that consists of an alpha subunit IFNGR1 $(90 \mathrm{kDa})$ and a beta subunit IFNGR2 $(60 \mathrm{kDa})(8,9)$. IFNGR1 binds to IFN $\gamma$ with high affinity whereas IFNGR2, although contributing to ligand binding and required for signaling, binds to IFN $\gamma$ with a significantly lower affinity $(9,10)$. The binding involves crosslinking two molecules each of IFNGR1 and IFNGR2. Subsequent to ligand binding, tyrosine kinases JAK1 (constitutively associated with IFNGR1) and JAK2 (constitutively associated with IFNGR2) become phosphorylated and subsequently activate STAT1 through phosphorylation $(9,11,12)$. It is then thought that phosphorylated, activated STAT1 translocates to the nucleus, where it mediates the transcription of IFN $\gamma$ associated proteins. The immediate effects of IFN $\gamma$ signaling occur rapidly as JAK1, JAK2, IFNGR1, and Stat1 are phosphorylated within $1 \mathrm{~min}$ of IFN $\gamma$ treatment (4).

\section{IFN $\gamma$ AND DISEASE}

Although IFN $\gamma$ signaling is critical for the generation of effector functions involved in the elimination of cancers and pathogenic microorganisms, the signaling must be carefully regulated to prevent excessive inflammation. The potential deleterious effects of IFN $\gamma$ signaling are also underscored by the fact that administration of IFN $\gamma$ to neonatal mice results in a lethal auto-inflammatory disease $(13,14)$. Significantly, excessive IFN $\gamma$ signaling has been associated with several autoimmune diseases including systemic lupus erythematosus (SLE) in both patients and rodent models of disease (15-18). SLE is a debilitating autoimmune disease with numerous medical manifestations including leucopenia, skin rashes, and damage to heart and kidneys. Moreover, ongoing 
research strategies for treatment of autoimmune diseases such a lupus include the use of antibodies targeting cytokines involved in disease progression, such as IFN $\gamma$ (15).

In addition to tolerance to self-tissues, the immune system must also maintain a balance between the elimination of infectious microorganisms and the tolerance of mutualistic microorganisms, which both regulate mammalian metabolic events and immune system development (19). Lipopolysaccharide (LPS) endotoxin, by Gram negative bacteria, and Staphylococcal enterotoxins (SE), by Gram positive bacteria, pose significant risks to human health by their capacity to dysregulate immune tolerance mechanisms and generate a lethal inflammatory environment, with excess production of IFN $\gamma(20)$. This is especially true in the case of combination challenges (infections are commonly polymicrobial), as it has been established that the combination challenges of Staphylococcal enterotoxin A (SEA) and LPS mediate more severe inflammatory environments in intact mice (20). SEA, which is a member of the superantigen toxins produced by Staphylococcus aureus, activates $\mathrm{T}$ lymphocytes possessing $\mathrm{T}$ cell receptors (TCR) of varying V-beta specificities, and is capable of mediating toxic shock syndrome. SEA crosslinks the antigen presenting cell MHC molecule, with the TCR V-beta chain, resulting in the production of abundant pro-inflammatory cytokines such as tumor necrosis factor alpha (TNF $\alpha)$, IFN $\gamma$, interleukin 1 (IL1), and IL6 (20). A hallmark of the adaptive immune system is antigenic specificity (21). Whereas a conventional $\mathrm{T}$ cell antigen mediates the activation of $\mathrm{T}$ lymphocytes on the order of one $\mathrm{T}$ cell clone/10,000 lymphocytes, as many as one in five $\mathrm{T}$ lymphocytes can be activated by the superantigen (22). Moreover the excessive activation of $\mathrm{T}$ lymphocyte clones occurs at a fraction of the concentration required to mediate conventional $\mathrm{T}$ lymphocyte activation. Notably, staphylococcal superantigens account for nearly $45 \%$ of all cases of food poisoning (23). IFN $\gamma$ and IL6 produced in response to microbial insult contribute to fever, nausea, vomiting, and diarrhea associated with the food poisoning. Given the potential for IFN $\gamma$ signaling to result in auto-immunity or excessive responses directed toward microorganisms, the immune system has developed regulatory mechanisms to limit IFN $\gamma$ signaling, which are potential targets of modulation in excessive inflammatory environments.

\section{REGULATORY T CELLS AND AUTO-IMMUNITY}

Despite the fact that $\mathrm{T}$ cells bearing specificity to self-peptides exist in nearly all individuals, autoimmune diseases are in limited numbers when compared to other sources of human disease $(24,25)$, thus underscoring the presence of tolerance mechanisms. Beyond central tolerance, one mechanism of active immune tolerance is Tregs. Although several distinct $\mathrm{T}$ cell populations possessing regulatory function have been described, $\mathrm{CD} 4^{+}$Tregs bearing the Foxp $3^{+}$transcription factor and constitutive expression of CD25 represent one of the lineages most characterized to date (26-28). However, it is important to note that Foxp3 alone is not sufficient to recapitulate the entire Treg signature (29), suggesting that additional Treg modulating genes likely remain to be characterized. Tregs have the capacity to suppress immune responses mediated by numerous cell types including macrophages, $\mathrm{CD} 4^{+} \mathrm{T}$ cells, and $\mathrm{CD}^{+} \mathrm{T}$ cells (30-34). The importance of functional Tregs in the prevention of auto-immunity is underscored by the fact that the adoptive transfer of Tregs into type 1 diabetes (35), experimental allergic encephalomyelitis (36), inflammatory bowel disease (37), and arthritis (38) rodent models resulted in the prevention/cure of disease.

Regulatory $\mathrm{T}$ cells, under the pseudonym suppressor $\mathrm{T}$ cells, have origins within the pioneering studies of Gershon followed by a rebirth powered largely by the Shevach and Sakaguchi laboratories (39). Tregs, along with other T lymphocytes, originate from the thymus as illustrated in seminal studies showing that day 3 thymectomy of neonatal mice resulted in the development of organ specific autoimmune diseases, which could be prevented by the administration of $\mathrm{CD} 4{ }^{+} \mathrm{CD} 25^{+} \mathrm{T}$ lymphocytes from healthy mice. Naturally occurring, thymic derived Foxp $3^{+}$Tregs constitute approximately $3-5 \%$ of the $\mathrm{CD} 4{ }^{+} \mathrm{CD}^{-}$thymocyte population (40) and are generally present within the medullary region of the thymus, the location of the most mature thymocytes (41). Further advances in the characterization of Tregs were made after the discovery that the lethal pathology observed in Scurfy mice was due to defective Foxp3. Scurfy mice, which lack CD $4^{+} \mathrm{CD} 25^{+}$Foxp $3^{+}$ Treg, die of a perinatal auto-inflammatory disease within 21 days after birth (39). Moreover, Scurfy mice die of massive infiltrations of activated leukocytes in multiple organs with autoimmune disease manifestations including lymphadenopathy, splenomegaly, anemia, and wasting (39). Notably, depletion of Th1 responses through the breeding of Scurfy mice to IFNGR1 or Tbet deficient backgrounds, results in prolonged survival of Scurfy mice (42). These results underscore the role that Tregs serve in critically regulating Th1 responses.

To date, there are two characterized populations of Foxp3 ${ }^{+}$ Tregs: naturally occurring Tregs that develop in the thymus (nTregs); and induced Tregs (iTregs) which are generated within peripheral organs from naïve $\mathrm{CD} 4^{+} \mathrm{CD} 25^{-}$Foxp $3^{-} \mathrm{T}$ lymphocytes $(39,43-45)$. Both nTregs and iTregs are thought to play a significant role in the regulation of immune responses, with nTregs focused on immunity directed against self-peptides and iTregs limiting immune pathology in response to commensal bacteria. Markers used to distinguish iTregs from nTregs include neuropilin1 (46) and the transcription factor Helios (47). Generation of peripheral Tregs can be mediated through the expansion of nTregs in the presence of endogenous peptides specific to Treg TCR, administration of low levels of cognate antigen, or transforming growth factor $\beta$ (TGF $\beta$ ) administration (48-51).

The survival and function of Tregs is critically dependent upon cytokines, such as Interleukin 2 (IL2) which is required for the survival of nTregs (52), and enhanced peripheral generation of iTregs $(53,54)$. In contrast, IL6 inhibits the generation of iTregs while favoring the generation of IL-17 secreting cells (55). Although Tregs can inhibit the production of IFN $\gamma$, Th1 associated cytokines IL27 and IFN $\gamma$ have been shown to increase TGF- $\beta$ induced Foxp3 expression $(56,57)$. However, other studies have shown that a Th1 response inhibits the generation of peripheral Tregs (58). It is possible that the ability of IFN $\gamma$ to up-regulate the IL2 receptor (CD25) (59) on lymphocytes may contribute to the increased FoxP3 expression observed, although further studies are necessary. It is thus clear that the differentiation, survival, and regulation of Tregs is dependent upon complex interactions with cytokines. 
Conversely, it is also clear that the regulation of inflammatory cytokines, such as IFN $\gamma$, is also critically dependent on Tregs.

\section{REGULATION OF IFN $\gamma$ SIGNALING THROUGH SOCS PROTEINS}

In addition to regulation of IFN $\gamma$ signaling by Tregs, it has become evident that the SOCS family of intracellular proteins also plays a pivotal role in such signaling (60). The SOCS protein family, identified in 1998, currently possesses eight family [SOCS1 to SOCS7 and cytokine-inducible SH2 protein (CIS)] members, which negatively regulate cellular responses to cytokines in a feedback inhibition fashion (61). SOCS proteins are induced by several cytokines and act to inhibit the signaling of the cytokine that mediated their generation (62). SOCS proteins act through at least two mechanisms: (1) SOCS1 possesses a kinase inhibitory region (KIR) that binds to JAKs, thus inhibiting further cytokine signaling and (2) SOCS1 contains a region known as the SOCS box, which targets bound proteins to the proteasome for degradation (60). Whereas all of the SOCS proteins possess a large central $\mathrm{SH} 2$ domain and a C-terminal SOCS box, the N-terminal (12amino acid long, adjacent to the $\mathrm{SH} 2$ domain) KIR region has only been identified in SOCS1 and SOCS3. While SOCS1 was initially identified as a regulator of IL6 signaling (63), it later became identified as a regulator of IFN $\gamma$. Mice lacking SOCS1 $\left(\mathrm{SOCS}^{-/-}\right.$) die within 21 days after birth, and are characterized by excessive IFN $\gamma$ signaling and massive inflammatory infiltration of auto-immune leukocytes into several organs including lungs, pancreas, liver, and heart (63). Neonatal lethality in SOCS1-1mice is believed to be due to excessive IFN $\gamma$ signaling, as the treatment of SOCS1 ${ }^{-/-}$mice with IFN $\gamma$ neutralizing antibodies or breeding to an IFN gamma deficient background rescues mice from neonatal lethality (64). SOCS1 deficient mice, made transgenic to express SOCS1 protein possessing the KIR region, but lacking the SOCS box, could survive peri-lethality with approximately $20 \%$ surviving long-term (65). Functionally, the regulation of IFN $\gamma$ signaling by SOCS1 is mediated by inhibition of JAK2 activity, but potentially also through the regulation of tyrosine kinases TYK2 and JAK1.

\section{SOCS1 AND AUTO-IMMUNITY}

In addition to the lethal, auto-inflammatory disease that occurs within SOCS1-KO mice, deficiencies in SOCS1 are also specifically linked to the onset and progression of SLE. SOCS1 ${ }^{-1-}$ mice, with forced expression of SOCS1 in B and T lymphocytes, and SOCS1 ${ }^{+/-}$mice survive perinatal lethality but develop a lupuslike disease $(66,67)$. The F1 progeny of New Zealand Black and New Zealand White (NZB/W) mice are a well-established model for spontaneous SLE (68). Notably, splenocytes present in diseased $\mathrm{NZB} / \mathrm{W}$ mice have a reduced capacity to up-regulate SOCS1 in response to IFN $\gamma$ (16). Moreover, the administration of a tolerogenic peptide, hCDR1, prevented lupus onset in NZB/W mice and enhanced production of SOCS1. In addition, the enhanced SOCS1 expression was correlated to reductions in IFN $\gamma$ production and STAT 1 activation in NZB/W mice (16). Although there is good evidence in rodent studies denoting a role for SOCS1 expression in the prevention of murine lupus, more studies are necessary to establish the translational value of this finding.
Moreover it has been shown that SOCS1 signaling plays an important role in moderating signaling directed toward microbial antigens, or microbial lymphocyte mitogens, as deficiencies in SOCS1 result in hyper-responsiveness to LPS (69). Although mice are more resistant to the individual effects of SEA or LPS than humans, immunological tolerance mechanisms regulating lethal inflammation in mice are overcome when co-challenged with SEA and LPS (20). Significantly, single administration of LPS to SOCS1 deficient mice resulted in lethal inflammation $(69,70)$, underscoring the critical role of SOCS1 in the maintenance of tolerance and prevention of lethal inflammation.

\section{Treg/SOCS1 CROSS-TALK REGULATION OF IFN $\gamma$ SIGNALING}

Auto-immunity is due largely to the cumulative effects of auto-antibody production (71), dysregulated pro-inflammatory cytokine signaling (72), and decreased regulatory $\mathrm{T}$ cell function (Tregs) $(73,74)$. It is likely, however, that the cumulative effects promoting auto-immunity are somewhat interdependent as we have previously shown that Tregs can inhibit auto-reactive $\mathrm{T}$ cell proliferation (75), auto-antibody production (34), and pro-inflammatory cytokine production (76). In similar fashion, immune system regulatory mechanisms are also interconnected. For example, thymic events not only mediate central tolerance, which limits the export of self-reactive $\mathrm{T}$ lymphocytes into the periphery, but also is the location of nTreg development. Notably, several recent studies have shown that SOCS1 and Foxp3 ${ }^{+}$Treg regulation of inflammation are also interconnected. Similar to Scurfy mice, survival of SOCS1 ${ }^{-1-}$ mice was greater with the adoptive transfer of wild-type conventional cells combined with Tregs compared to transfers of Tregs alone $(77,78)$. In addition, Scurfy and SOCS1 deficient mice both have significantly expanded populations of peripheral CD $44{ }^{\mathrm{hi}} \mathrm{CD} 4^{+} \mathrm{T}$ lymphocytes $(42,64)$. The presence of CD $44^{\mathrm{hi}}$ cells is indicative of homeostatic proliferation. Moreover, recent microRNA (miR) studies link Tregs and SOCS1. MicroRNA 155 (miR-155) is highly expressed in Tregs, and is regulated by the transcription factor Foxp3 (79). Foxp3 binds to the promoter region of miR-155 host gene bic, mediating miR-155 up-regulation, which is then thought to down-regulate SOCS1 expression $(80,81)$. High levels of Foxp3 therefore drive up miR-155 expression, down-modulate SOCS1, and enhance the thymic development of Tregs $(78,81,82)$. Notably, however, miR155 is not required for peripheral survival of Tregs or suppressor function (83). Although Rag gene deficient mice are free of spontaneous colitis, SOCS1 ${ }^{-1-} \operatorname{Rag} 2^{-1-}$ mice develop severe colitis (84). However, the adoptive transfer of IL10-producing-Tregs is sufficient to prevent colitis in SOCS1 $1^{-/} \operatorname{Rag} 2^{-1-}$ mice (84), again underscoring the interconnected nature of SOCS1 signaling and regulatory Tregs in the regulation of immune responses. Significantly, onset of lethal auto-inflammatory disease in SOCS1 ${ }^{-1-}$ mice is correlated with a decrease in Foxp $3^{+}$Tregs, thereby suggesting a critical role of SOCS1 in the peripheral stability of Tregs (78). Moreover, in the absence of SOCS1, Foxp $3^{+} \mathrm{T}$ cells produce the inflammatory cytokines IL-17 and IFN $\gamma(85)$. Further, recent studies show that Ubc13, lysine specific ubiquitin-conjugating enzyme, regulates SOCS1 expression and IL10 production in Tregs (86). This finding is significant as Ubc13 mutation does not affect Foxp3 expression in T lymphocytes; however, Ubc13 deficient Foxp $3^{+} \mathrm{T}$ 


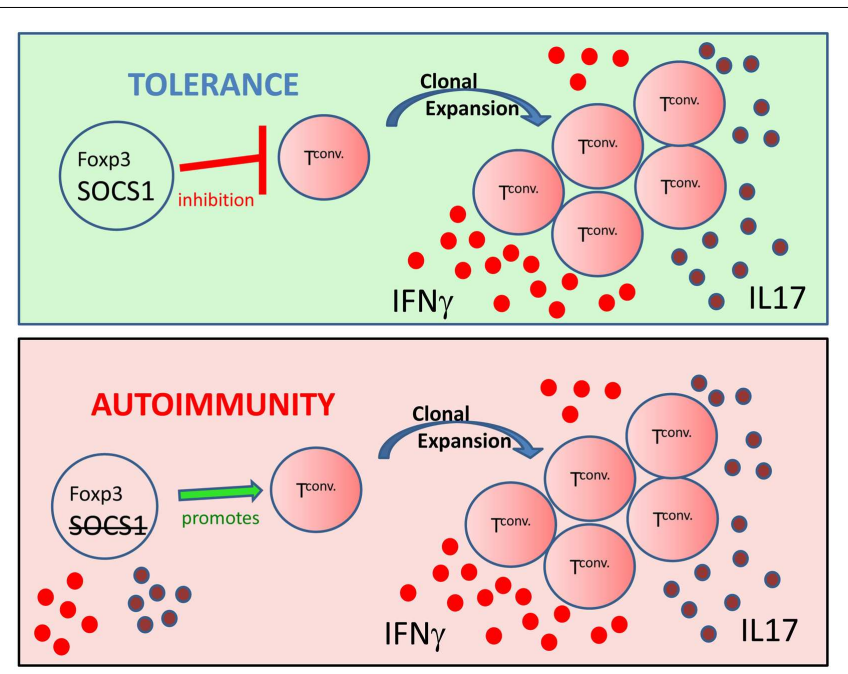

FIGURE 1 | From inhibitor to contributor: figure representing the critical role of SOCS1 in the stability and function of Foxp3 ${ }^{+}$Tregs. (Top) Tregs possessing Foxp3 and SOCS1 inhibit clonal expansion and the production of inflammatory effector cytokines such as IFN $\gamma$ (red circles) and IL-17 (purple circles) by conventional T cells (Tconv), thus maintaining immune homeostasis. (Bottom) T cells possessing Foxp3, but lacking SOCS1, produce inflammatory cytokines and promote Tconv generation of an inflammatory environment. Thus exTregs expressing Foxp3, but lacking SOCS1, can promote auto-immunity.

lymphocytes acquire IFN $\gamma$ or IL-17 producing inflammatory phenotypes (86). Inflammation is regulated through two important arms of the immune system; the intracellular proteins SOCS1 (60, 63) and Foxp $3^{+}$Tregs (52). Significantly, the studies presented herein implicate a role of SOCS1 in the stability of Tregs, suggesting that loss of SOCS1 function also inhibits Treg function (Figure 1).

\section{SOCS MIMETICS AS THERAPEUTICS AGAINST AUTO-IMMUNITY AND INFLAMMATION}

Given the critical importance of SOCS1 in moderating IFN $\gamma$ signaling directly, and in stabilizing the Treg phenotype $(78,86)$, methods to modulate SOCS1 function would likely have significant therapeutic potential. Two factors limit the direct use of SOCS1 protein as a therapeutic: (1) SOCS1 is extremely difficult to produce in pure form and (2) since it functions intracellularly, there is also the challenge of it being internalized by cells so that interaction with JAKs can occur.

We have addressed these problems with SOCS1 by development of small peptide SOCS1 mimetics. The focus has been on the 12-amino acid KIR of SOCS1 where we initially developed a 12-residue peptide based on a hydropathic complementary algorithm (87). The resultant tyrosine kinase inhibitory peptide (Tkip), WLVFFVIFYFFR, specifically bound to the activation loop sequence, ${ }^{1001}$ LPQDKEYYKVKEP, of JAK2 (88). Tkip blocked autophosphorylation of JAK2 as well as that of JAK2 phosphorylation of receptor subunit IFNGR1 and the corresponding transcription factor STAT $1 \alpha$. Tkip also blocked phosphorylation of the epidermal growth factor tyrosine kinase receptor (EGFR), whose function is also inhibited by SOCS1 (87). Like SOCS1, however,
Tkip did not inhibit receptor tyrosine kinase VEGF kinase activity (87). Attachment of a lipophilic palmitate residue to Tkip (lipoTkip) allowed cell penetration for study of function. In this regard, cells treated with lipo-Tkip showed inhibition of IFN $\gamma$ induced anti-viral activity against EMC virus in WEHI-3 cells and downregulation of IFN $\gamma$ induced expression of MHC class I on WISH cells (87).

Tkip protected mice against experimental auto-immune encephalomyelitis (EAE), a mouse model of multiple sclerosis, both in terms of induction of acute EAE, relapsing/remitting EAE, and chronic EAE (89). Importantly, it also showed therapeutic efficacy when treatment was initiated after appearance of paralytic symptoms and central nervous system (CNS) pathology (89). These studies involved injection of lipo-Tkip at $63 \mu \mathrm{g} / \mathrm{dose}$ IP every other day and were the first to show that a SOCS1 mimetic had therapeutic potential in treating an auto-immune disorder.

As indicated, Tkip was developed based on the hydropathic complementary algorithm without an initial consideration of SOCS1-KIR. However, of three sites of homology between Tkip and KIR, residues F56 and F59 of KIR are of particular interest as mutational analysis has shown that they are critical for KIR binding to JAK2 (88). We thus synthesized SOCS1-KIR and determined its binding to JAK2 activation loop, JAK2(1001-1013), with phosphorylated and non-phosphorylated tyrosine 1007 (88). SOCS1-KIR bound to phosphorylated activation loop, pJAK2(1001-1013), with higher affinity than to unphosphorylated activation loop. Unlike Tkip, however, SOCS1-KIR did not block JAK2 autophosphorylation, but like Tkip it did block STAT1 $\alpha$ phosphorylation. Thus, Tkip and SOCS1-KIR both recognized JAK2 activation loop, but not in the same precise manner.

We synthesized lipo-SOCS1-KIR and determined its therapeutic efficacy in a murine relapsing/remitting model of EAE. Treatment of SJL/J mice with SOCS1-KIR beginning 12 days postimmunization with myelin basic protein (MBP) resulted in minimal symptoms of EAE, while most control treated mice developed paraplegia (90). Th1 and Th17 cells via IFN $\gamma$ and IL-17, respectively, are thought to play critical roles in the pathogenesis of EAE and multiple sclerosis (91). SOCS1-KIR treatment suppressed interleukin-17A (IL-17A) production by MBP-specific lymphocytes, as well as MBP-induced lymphocyte proliferation. When treated with IL-23, a key cytokine in the terminal differentiation of IL-17-producing cells, MBP-sensitized cells produced IL-17A and IFN $\gamma$; SOCS1-KIR was able to inhibit the production of these cytokines (90). SOCS1-KIR also blocked IL-23 and IL-17A activation of STAT3. There is a deficiency of SOCS1 and SOCS3 expression in $\mathrm{CD}^{+}{ }^{+} \mathrm{T}$ cells that infiltrate the CNS in EAE, reflecting a deficiency in regulation. Consistent with therapeutic efficacy, SOCS1-KIR reversed the cellular infiltration of the CNS that is associated with EAE (90). These results with an auto-immune neurological model suggest the potential of SOCS mimetics as therapeutics for auto-immune and inflammatory disorders.

The immuno-modulatory potential of lipo-SOCS1-KIR was also examined in SOCS1-1- mice, which die within 21 days of birth of an IFN $\gamma$ mediated, auto-inflammatory disease (78). Significantly, lipo-SOCS1-KIR administration, in combination with CD4 $\mathrm{T}$ cell adoptive transfer, was sufficient to extend the survival of SOCS1 $1^{-l-}$ mice (78). The survival of the SOCS1 ${ }^{-/-}$mice 
receiving the combined treatment was similar to previous studies utilizing mice where SOCS1 contained a KIR region, but lacked a SOCS box (65). Moreover the SOCS1-KIR/CD4 T cell adoptive transfer treatment, decreased leukocytic infiltrations of organs, decreased inflammation overall, and decreased IFN $\gamma$ serum levels. In particular, the combined treatment mediated a very noticeable increase of peripheral Foxp $3^{+}$Tregs, both number and frequency, which correlated with the increased survival of $\mathrm{SOCS}^{-/-}$ mice (78). This study suggests that administration of mimetics of SOCS1 may potentially enhance Treg mediated regulation of the immune response.

There is also evidence that SOCS1-KIR has therapeutic potential in auto-immune/inflammatory skin disorders such as psoriasis (92). First, others have confirmed the mimetic activity of SOCS1KIR and have made modifications in residues for a SOCS1-KIR variant that possessed specific activity similar to that of SOCS1KIR (93). IFN $\gamma$ plays a key role in psoriasis related pathogenesis of the skin via its activation of keratinocytes (94). Overexpression of SOCS1 in keratinocytes has previously been shown to reduce the inflammation and to restore homeostasis to the skin (95). The SOCS1-KIR mimetic variant inhibited IFN $\gamma$ induced inflammation in human keratinocytes, which was reflected by inhibition of JAK2, IFNGR1, and STAT1 $\alpha$ phosphorylation. The inhibition at the level of JAK2 autophosphorylation suggests that the SOCS1KIR variant (called PS-5) functioned similarly to that of Tkip (92). Consistent with reduced phosphorylation, PS-5 reduced ICAM-1, HLA-DR, CXCL-10, and CCL-2 inflammatory gene expression. These SOCS1 mimetic results suggest the potential of treatment of psoriasis-type disorders with SOCS1 mimetics.

\section{FROM SOCS1-KIR TO A SOCS1 ANTAGONIST}

The fact that KIR of SOCS1, SOCS1-KIR, can bind to a peptide, pJAK2(1001-1013), that corresponds to the activation loop of phosphorylated JAK2, pJAK2, raised the possibility that pJAK2(1001-1013) could function as an antagonist of SOCS1 (88). We have thus demonstrated under four different types of experiments that pJAK2(1001-1013) possessed SOCS1 antagonist properties. First, pJAK2(1001-1013) enhanced suboptimal IFN $\gamma$ activity. Second, prostate cancer cells transfected for constitutive production of SOCS1 protein had reduced activation of STAT3 by IL6 treatment. pJAK2(1001-1013) reversed the SOCS1 effect. Third, pJAK2(1001-1013) enhanced IFN $\gamma$ activation of the luciferase reporter gene via the GAS promoter. Fourth, pJAK2(1001-1013) enhanced antigen-specific splenocyte proliferation. Treatment of cells with IFN $\gamma$ resulted in activation of the SOCS 1 gene in approximately $90 \mathrm{~min}$ and it has been proposed that this is associated with the physiological attenuation of the IFN $\gamma$ response by SOCS1 (64). Consistent with this, it has been reported that siRNA inhibition of SOCS1 expression in bone marrow dendritic cells resulted in enhanced cytotoxic $\mathrm{T}$ lymphocyte (CTL) activity and IFN $\gamma$ production by ELISPOT, culminating in enhancement of antitumor immunity (96).

Recently, the SOCS1 antagonist was shown to enhance antigenpresentation and CTL activity of human dendritic cells (97). Specifically, pJAK2(1001-1013) up-regulated the expression of the maturation marker (CD83) and co-stimulatory molecule (CD86) of monocyte-derived mature dendritic cells ( $\mathrm{mDCs})$, potentiated

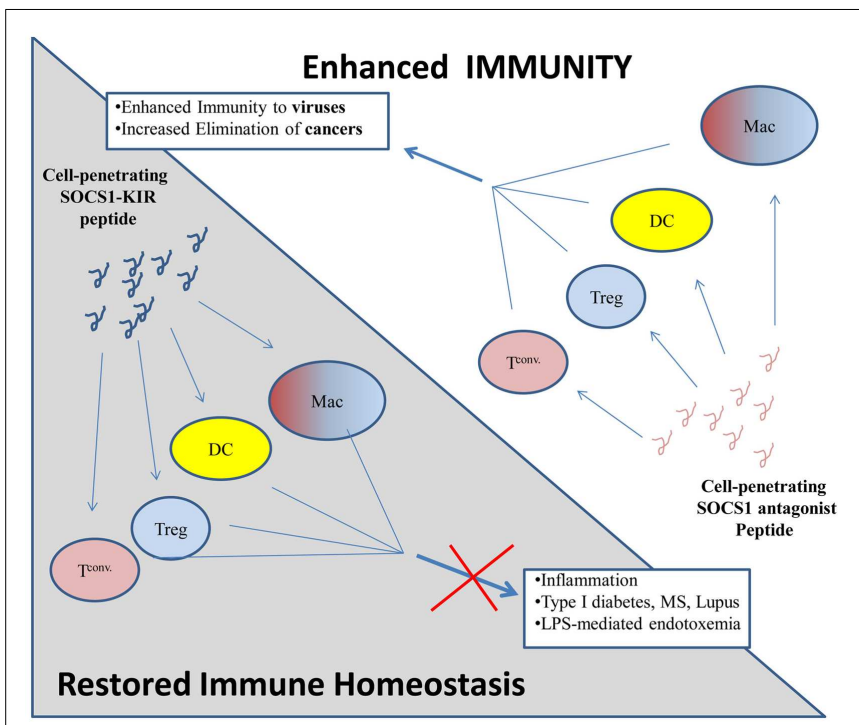

FIGURE 2 | Proposed model of immune regulation by SOCS1 mimetic peptides and antagonists. (Top) Cell penetrating SOCS1 antagonist peptides (pink loop) are internalized by various immune cells: macrophages (Mac), dendritic cells (DCs), regulatory T cells (Treg), and conventional T cell ( $T$ conv) where they antagonize the immuno-suppressive effects of native SOCS1. Inflammatory processes are enhanced, thus facilitating the elimination of cancers and viral infections. (Bottom) Cell penetrating SOCS1-KIR, which mimics the function of native SOCS1 (blue loop), is internalized by various immune cells (as above) where it enhances the immuno-suppressive effects of native SOCS1. Inflammatory processes are inhibited by cell penetrating SOCS1-KIR, thus inhibiting diseases which require dysregulated inflammation.

the capacity of $\mathrm{mDCs}$ to induce $\mathrm{T}$ cell proliferation, stimulated the secretion of pro-inflammatory cytokines, and enhanced the cytotoxicity of tumor cell antigen-specific CTLs activated by human gastric cancer cell total RNA-electroporated mDCs. At the level of transcription, pJAK2(1001-1013) enhanced STAT1 activation.

Thus, just as the SOCS mimetics can inhibit inflammatory cytokine activity in auto-immunity, the SOCS1 antagonist can enhance immune activity for treatment of infections and cancers (Figure 2).

\section{CONCLUSION}

The immune regulatory mechanisms of Tregs and SOCS1 play a critical role in maintaining the balance between the effective clearances of pathogens and maintaining tolerance to self-tissues and mutualistic microorganisms. Notably, recent studies implicate a significant role of SOCS1 in the peripheral survival and phenotypic stability of Tregs, suggesting that defects in the SOCS1 arm of immune homeostasis will also cause defects in the Treg arm of homeostasis. Moreover, the use of peptides which mimic SOCS1 signaling may have therapeutic efficacy in the treatment of autoimmunity by restoring the SOCS1 and Treg immuno-modulatory pathways.

\section{REFERENCES}

1. Miller CH, Maher SG, Young HA. Clinical use of interferon-gamma. Ann NY Acad Sci (2009) 1182:69-79. doi:10.1111/j.1749-6632.2009.05069.x 
2. Martin-Orozco N, Dong C. The IL-17/IL-23 axis of inflammation in cancer: friend or foe? Curr Opin Investig Drugs (2009) 10(6):543-9.

3. Miyara M, Sakaguchi S. Natural regulatory T cells: mechanisms of suppression. Trends Mol Med (2007) 13(3):108-16. doi:10.1016/j.molmed.2007.01.003

4. Schroder K, Hertzog PJ, Ravasi T, Hume DA. Interferon-gamma: an overview of signals, mechanisms and functions. J Leukoc Biol (2004) 75(2):163-89. doi:10.1189/jlb.0603252

5. Kominsky SL, Hobeika AC, Lake FA, Torres BA, Johnson HM. Down-regulation of neu/HER-2 by interferon-gamma in prostate cancer cells. Cancer Res (2000) 60(14):3904-8.

6. Hobeika AC, Etienne W, Cruz PE, Subramaniam PS, Johnson HM. IFNgamma induction of p21WAF1 in prostate cancer cells: role in cell cycle, alteration of phenotype and invasive potential. Int J Cancer (1998) 77(1):138-45. doi:10.1002/(SICI)1097-0215(19980703)77:1<138::AID-IJC21>3.0.CO;2-9

7. BelkaidY, Rouse BT. Natural regulatory T cells in infectious disease. Nat Immunol (2005) 6(4):353-60. doi:10.1038/ni1181

8. Pestka S, Kotenko SV, Muthukumaran G, Izotova LS, Cook JR, Garotta G. The interferon gamma (IFN-gamma) receptor: a paradigm for the multichain cytokine receptor. Cytokine Growth Factor Rev (1997) 8(3):189-206. doi:10.1016/S1359-6101(97)00009-9

9. Bach EA, Aguet M, Schreiber RD. The IFN gamma receptor: a paradigm for cytokine receptor signaling. Annu Rev Immunol (1997) 15:563-91. doi:10.1146/ annurev.immunol.15.1.563

10. Hemmi S, Bohni R, Stark G, Di Marco F, Aguet M. A novel member of the interferon receptor family complements functionality of the murine interferon gamma receptor in human cells. Cell (1994) 76(5):803-10. doi:10.1016/00928674(94)90355-7

11. Bach EA, Tanner JW, Marsters S, Ashkenazi A, Aguet M, Shaw AS, et al. Ligandinduced assembly and activation of the gamma interferon receptor in intact cells. Mol Cell Biol (1996) 16(6):3214-21.

12. Farrar MA, Fernandez-Luna J, Schreiber RD. Identification of two regions within the cytoplasmic domain of the human interferon-gamma receptor required for function. J Biol Chem (1991) 266(29):19626-35.

13. Gresser I, Tovey MG, Maury C, Chouroulinkov I. Lethality of interferon preparations for newborn mice. Nature (1975) 258(5530):76-8. doi:10.1038/258076a0

14. Gresser I, Maury C, Tovey M, Morel-Maroger L, Pontillon F. Progressive glomerulonephritis in mice treated with interferon preparations at birth. Nature (1976) 63(5576):420-2. doi:10.1038/263420a0

15. Ledford H. After half-century's wait, approval paves path for new lupus drugs. Nat Med (2011) 17(4):400. doi:10.1038/nm0411-400a

16. Sharabi A, Sthoeger ZM, Mahlab K, Lapter S, Zinger H, Mozes E. A tolerogenic peptide that induces suppressor of cytokine signaling (SOCS)-1 restores the aberrant control of IFN-gamma signaling in lupus-affected (NZB x NZW)F1 mice. Clin Immunol (2009) 133(1):61-8. doi:10.1016/j.clim.2009.06.010

17. Wang B, Andre I, Gonzalez A, Katz JD, Aguet M, Benoist C, et al. Interferongamma impacts at multiple points during the progression of autoimmune diabetes. Proc Natl Acad Sci U S A (1997) 94(25):13844-9. doi:10.1073/pnas.94.25. 13844

18. Kanagawa O, Xu G, Tevaarwerk A, Vaupel BA. Protection of nonobese diabetic mice from diabetes by gene(s) closely linked to IFN-gamma receptor loci. J Immunol (2000) 164(7):3919-23.

19. Kunisawa J, Kiyono H. Peaceful mutualism in the gut: revealing key commensal bacteria for the creation and maintenance of immunological homeostasis. Cell Host Microbe (2011) 9(2):83-4. doi:10.1016/j.chom.2011.01.012

20. Kissner TL, Cisney ED, Ulrich RG, Fernandez S, Saikh KU. Staphylococcal enterotoxin A induction of pro-inflammatory cytokines and lethality in mice is primarily dependent on MyD88. Immunology (2010) 130(4):516-26. doi:10.1111/j.1365-2567.2010.03249.x

21. Picca CC, Larkin J III, Boesteanu A, Lerman MA, Rankin AL, Caton AJ. Role of TCR specificity in CD4+ CD25+ regulatory T-cell selection. Immunol Rev (2006) 212:74-85. doi:10.1111/j.0105-2896.2006.00416.x

22. Johnson HM, Russell JK, Pontzer CH. Staphylococcal enterotoxin microbial superantigens. FASEB J (1991) 5(12):2706-12.

23. Johnson HM, Russell JK, Pontzer CH. Superantigens in human disease. Sci Am (1992) 266(4):92-5. doi:10.1038/scientificamerican0492-92

24. Walsh SJ, Rau LM. Autoimmune diseases: a leading cause of death among young and middle-aged women in the United States. Am J Public Health (2000) 90(9):1463-6. doi:10.2105/AJPH.90.9.1463
25. Cooper GS, Bynum ML, Somers EC. Recent insights in the epidemiology of autoimmune diseases: improved prevalence estimates and understanding of clustering of diseases. J Autoimmun (2009) 33(3-4):197-207. doi:10.1016/j.jaut. 2009.09.008

26. Takahashi T, Kuniyasu Y, Toda M, Sakaguchi N, Itoh M, Iwata M, et al. Immunologic self-tolerance maintained by CD25+CD4+ naturally anergic and suppressive $\mathrm{T}$ cells: induction of autoimmune disease by breaking their anergic/suppressive state. Int Immunol (1998) 10(12):1969-80. doi:10.1093/intimm/ 10.12.1969

27. Schubert LA, Jeffery E, Zhang Y, Ramsdell F, Ziegler SF. Scurfin (FOXP3) acts as a repressor of transcription and regulates T cell activation. J Biol Chem (2001) 276(40):37672-9. doi:10.1074/jbc.M104521200

28. Fontenot JD, Gavin MA, Rudensky AY. Foxp3 programs the development and function of CD4+CD25+ regulatory T cells. Nat Immunol (2003) 4(4):330-6. doi:10.1038/ni904

29. Feuerer M, Hill JA, Mathis D, Benoist C. Foxp3+ regulatory T cells: differentiation, specification, subphenotypes. Nat Immunol (2009) 10(7):689-95. doi:10.1038/ni.1760

30. Piccirillo CA, Shevach EM. Cutting edge: control of CD8+ T cell activation by CD4+CD25+ immunoregulatory cells. J Immunol (2001) 167(3):1137-40.

31. Suri-Payer E, Amar AZ, Thornton AM, Shevach EM. CD4+CD25+ T cells inhibit both the induction and effector function of autoreactive $\mathrm{T}$ cells and represent a unique lineage of immunoregulatory cells. J Immunol (1998) 160(3):1212-8.

32. Tiemessen MM, Jagger AL, Evans HG, van Herwijnen MJ, John S, Taams LS. CD4+CD25+Foxp3+ regulatory T cells induce alternative activation of human monocytes/macrophages. Proc Natl Acad Sci U S A (2007) 104(49):19446-51. doi:10.1073/pnas.0706832104

33. Lim HW, Hillsamer P, Banham AH, Kim CH. Cutting edge: direct suppression of B cells by CD4+ CD25+ regulatory T cells. J Immunol (2005) 175(7):4180-3.

34. Guay HM, Larkin J III, Picca CC, Panarey L, Caton AJ. Spontaneous autoreactive memory B cell formation driven by a high frequency of autoreactive CD4+ T cells. J Immunol (2007) 178(8):4793-802.

35. Tang Q, Henriksen KJ, Bi M, Finger EB, Szot G, Ye J, et al. In vitro-expanded antigen-specific regulatory $\mathrm{T}$ cells suppress autoimmune diabetes. J Exp Med (2004) 199(11):1455-65. doi:10.1084/jem.20040139

36. Selvaraj RK, Geiger TL. Mitigation of experimental allergic encephalomyelitis by TGF-beta induced Foxp3+ regulatory T lymphocytes through the induction of anergy and infectious tolerance. J Immunol (2008) 180(5):2830-8.

37. Powrie F, Read S, Mottet C, Uhlig H, Maloy K. Control of immune pathology by regulatory T cells. Novartis Found Symp (2003) 252:92-8. doi:10.1002/ 0470871628.ch7

38. Morgan ME, Flierman R, van Duivenvoorde LM, Witteveen HJ, van Ewijk W, van Laar JM, et al. Effective treatment of collagen-induced arthritis by adoptive transfer of CD25+ regulatory T cells. Arthritis Rheum (2005) 52(7):2212-21. doi:10.1002/art.21195

39. Rouse BT. Regulatory $\mathrm{T}$ cells in health and disease. J Intern Med (2007) 262(1):78-95. doi:10.1111/j.1365-2796.2007.01836.x

40. Shevach EM. Certified professionals: CD4(+)CD25(+) suppressor T cells. J Exp Med (2001) 193(11):F41-6. doi:10.1084/jem.193.11.F41

41. Fontenot JD, Rasmussen JP, Williams LM, Dooley JL, Farr AG, Rudensky AY. Regulatory $\mathrm{T}$ cell lineage specification by the forkhead transcription factor foxp3. Immunity (2005) 22(3):329-41. doi:10.1016/j.immuni.2005.01.016

42. Suscovich TJ, Perdue NR, Campbell DJ. Type-1 immunity drives early lethality in scurfy mice. Eur J Immunol (2012) 42(9):2305-10. doi:10.1002/eji.201242391

43. Itoh M, Takahashi T, Sakaguchi N, Kuniyasu Y, Shimizu J, Otsuka F, et al. Thymus and autoimmunity: production of CD25+CD4+ naturally anergic and suppressive $\mathrm{T}$ cells as a key function of the thymus in maintaining immunologic self-tolerance. J Immunol (1999) 162(9):5317-26.

44. Jordan MS, Boesteanu A, Reed AJ, Petrone AL, Holenbeck AE, Lerman MA, et al. Thymic selection of CD4+CD25+ regulatory $\mathrm{T}$ cells induced by an agonist self-peptide. Nat Immunol (2001) 2(4):301-6. doi:10.1038/86302

45. Larkin J III, Rankin AL, Picca CC, Riley MP, Jenks SA, Sant AJ, et al. CD4+CD25+ regulatory $\mathrm{T}$ cell repertoire formation shaped by differential presentation of peptides from a self-antigen. J Immunol (2008) 180(4):2149-57.

46. Yadav M, Louvet C, Davini D, Gardner JM, Martinez-Llordella M, BaileyBucktrout S, et al. Neuropilin-1 distinguishes natural and inducible regulatory $\mathrm{T}$ cells among regulatory T cell subsets in vivo. J Exp Med (2012) 209(10):1713-22. doi:10.1084/jem.20120822 
47. Feuerer M, Hill JA, Kretschmer K, von Boehmer H, Mathis D, Benoist C. Genomic definition of multiple ex vivo regulatory T cell subphenotypes. Proc Natl Acad Sci U S A (2010) 107(13):5919-24. doi:10.1073/pnas. 1002006107

48. Cozzo C, Larkin J III, Caton AJ. Cutting edge: self-peptides drive the peripheral expansion of CD4+CD25+ regulatory T cells. J Immunol (2003) 171(11):5678-82.

49. Curotto de Lafaille MA, Kutchukhidze N, Shen S, Ding Y, Yee H, Lafaille JJ. Adaptive Foxp3+ regulatory $\mathrm{T}$ cell-dependent and -independent control of allergic inflammation. Immunity (2008) 29(1):114-26. doi:10.1016/j.immuni.2008.05. 010

50. Curotto de Lafaille MA, Lino AC, Kutchukhidze N, Lafaille JJ. CD25- T cells generate CD25+Foxp3+ regulatory T cells by peripheral expansion. J Immunol (2004) 173(12):7259-68.

51. Chen W, Jin W, Hardegen N, Lei KJ, Li L, Marinos N, et al. Conversion of peripheral CD4+CD25- naive T cells to CD4+CD25+ regulatory T cells by TGF-beta induction of transcription factor Foxp3. J Exp Med (2003) 198(12):1875-86. doi:10.1084/jem.20030152

52. Shevach EM, Di Paolo RA, Andersson J, Zhao DM, Stephens GL, Thornton AM. The lifestyle of naturally occurring CD4+ CD25+ Foxp3+ regulatory T cells. Immunol Rev (2006) 212:60-73. doi:10.1111/j.0105-2896.2006.00415.x

53. Horwitz DA, Zheng SG, Gray JD. Natural and TGF-beta-induced Foxp3(+)CD4(+) CD25(+) regulatory $\mathrm{T}$ cells are not mirror images of each other. Trends Immunol (2008) 29(9):429-35. doi:10.1016/j.it.2008.06.005

54. Zheng SG, Wang J, Wang P, Gray JD, Horwitz DA. IL-2 is essential for TGF-beta to convert naive CD4+CD25- cells to CD25+Foxp3+ regulatory $\mathrm{T}$ cells and for expansion of these cells. J Immunol (2007) 178(4):2018-27.

55. Veldhoen M, Hocking RJ, Atkins CJ, Locksley RM, Stockinger B. TGFbeta in the context of an inflammatory cytokine milieu supports de novo differentiation of IL-17-producing T cells. Immunity (2006) 24(2):179-89. doi:10.1016/j.immuni. 2006.01.001

56. Ouaked N, Mantel PY, Bassin C, Burgler S, Siegmund K, Akdis CA, et al. Regulation of the foxp3 gene by the Th1 cytokines: the role of IL-27-induced STAT1. J Immunol (2009) 182(2):1041-9.

57. Wang Z, Hong J, Sun W, Xu G, Li N, Chen X, et al. Role of IFN-gamma in induction of Foxp3 and conversion of CD4+ CD25- T cells to CD4+ Tregs. J Clin Invest (2006) 116(9):2434-41.

58. Caretto D, Katzman SD, Villarino AV, Gallo E, Abbas AK. Cutting edge: the Th1 response inhibits the generation of peripheral regulatory T cells. J Immunol (2010) 184(1):30-4. doi:10.4049/jimmunol.0903412

59. Johnson HM, Farrar WL. The role of a gamma interferon-like lymphokine in the activation of $\mathrm{T}$ cells for expression of interleukin 2 receptors. Cell Immunol (1983) 75(1):154-9. doi:10.1016/0008-8749(83)90314-3

60. Yoshimura A. Regulation of cytokine signaling by the SOCS and Spred family proteins. Keio J Med (2009) 58(2):73-83. doi:10.2302/kjm.58.73

61. Yoshimura A, Suzuki M, Sakaguchi R, Hanada T, Yasukawa H. SOCS, Inflammation, and autoimmunity. Front Immunol (2012) 3:20. doi:10.3389/fimmu.2012. 00020

62. Ilangumaran S, Rottapel R. Regulation of cytokine receptor signaling by SOCS1. Immunol Rev (2003) 192:196-211. doi:10.1034/j.1600-065X.2003.00020.x

63. Croker BA, Kiu H, Nicholson SE. SOCS regulation of the JAK/STAT signalling pathway. Semin Cell Dev Biol (2008) 19(4):414-22. doi:10.1016/j.semcdb.2008. 07.010

64. Yoshimura A, Naka T, Kubo M. SOCS proteins, cytokine signalling and immune regulation. Nat Rev Immunol (2007) 7(6):454-65. doi:10.1038/nri2093

65. Zhang JG, Metcalf D, Rakar S, Asimakis M, Greenhalgh CJ, Willson TA, et al. The SOCS box of suppressor of cytokine signaling-1 is important for inhibition of cytokine action in vivo. Proc Natl Acad Sci U S A (2001) 98(23):13261-5. doi:10.1073/pnas.231486498

66. Hanada T, Yoshida H, Kato S, Tanaka K, Masutani K, Tsukada J, et al. Suppressor of cytokine signaling- 1 is essential for suppressing dendritic cell activation and systemic autoimmunity. Immunity (2003) 19(3):437-50. doi:10.1016/S10747613(03)00240-1

67. Fujimoto M, Tsutsui H, Xinshou O, Tokumoto M, Watanabe D, Shima Y, et al. Inadequate induction of suppressor of cytokine signaling-1 causes systemic autoimmune diseases. Int Immunol (2004) 16(2):303-14. doi:10.1093/intimm/ dxh030
68. Morel L. Genetics of SLE: evidence from mouse models. Nat Rev Rheumatol (2010) 6(6):348-57. doi:10.1038/nrrheum.2010.63

69. Kinjyo I, Hanada T, Inagaki-Ohara K, Mori H, Aki D, Ohishi M, et al. SOCS1/JAB is a negative regulator of LPS-induced macrophage activation. Immunity (2002) 17(5):583-91. doi:10.1016/S1074-7613(02)00446-6

70. Nakagawa R, Naka T, Tsutsui H, Fujimoto M, Kimura A, Abe T, et al. SOCS1 participates in negative regulation of LPS responses. Immunity (2002) 17(5):677-87. doi:10.1016/S1074-7613(02)00449-1

71. Teichmann LL, Ols ML, Kashgarian M, Reizis B, Kaplan DH, Shlomchik MJ. Dendritic cells in lupus are not required for activation of $\mathrm{T}$ and $\mathrm{B}$ cells but promote their expansion, resulting in tissue damage. Immunity (2010) 33(6):967-78. doi:10.1016/j.immuni.2010.11.025

72. Blanco P, Palucka AK, Gill M, Pascual V, Banchereau J. Induction of dendritic cell differentiation by IFN-alpha in systemic lupus erythematosus. Science (2001) 294(5546):1540-3. doi:10.1126/science. 1064890

73. Miyara M, Amoura Z, Gorochov G. Human lupus, fewer Treg cells indeed: comment on the article by Venigalla et al. Arthritis Rheum (2009) 60(2):630. doi:10.1002/art.24287

74. Blanco P, Palucka AK, Pascual V, Banchereau J. Dendritic cells and cytokines in human inflammatory and autoimmune diseases. Cytokine Growth Factor Rev (2008) 19(1):41-52. doi:10.1016/j.cytogfr.2007.10.004

75. Larkin J III, Picca CC, Caton AJ. Activation of CD4+ CD25+ regulatory T cell suppressor function by analogs of the selecting peptide. Eur J Immunol (2007) 37(1):139-46. doi:10.1002/eji.200636577

76. Lerman MA, Larkin J III, Cozzo C, Jordan MS, Caton AJ. CD4(+) CD25(+) regulatory $\mathrm{T}$ cell repertoire formation in response to varying expression of a neo-self-antigen. J Immunol (2004) 173(1):236-44.

77. Zheng P, Chang X, Lu Q, Liu Y. Cytopenia and autoimmune diseases: a vicious cycle fueled by mTOR dysregulation in hematopoietic stem cells. J Autoimmun (2013) 41:182-7. doi:10.1016/j.jaut.2012.12.011

78. Collins EL, Jager LD, Dabelic R, Benitez P, Holdstein K, Lau K, et al. Inhibition of SOCS1-/- lethal autoinflammatory disease correlated to enhanced peripheral Foxp3+ regulatory T cell homeostasis. J Immunol (2011) 187(5):2666-76. doi:10.4049/jimmunol.1003819

79. Cobb BS, Hertweck A, Smith J, O'Connor E, Graf D, Cook T, et al. A role for Dicer in immune regulation. J Exp Med (2006) 203(11):2519-27. doi:10.1084/ jem. 20061692

80. Marson A, Kretschmer K, Frampton GM, Jacobsen ES, Polansky JK, MacIsaac $\mathrm{KD}$, et al. Foxp3 occupancy and regulation of key target genes during T-cell stimulation. Nature (2007) 445(7130):931-5. doi:10.1038/nature05478

81. Lu LF, Thai TH, Calado DP, Chaudhry A, Kubo M, Tanaka K, et al. Foxp3dependent microRNA155 confers competitive fitness to regulatory $\mathrm{T}$ cells by targeting SOCS1 protein. Immunity (2009) 30(1):80-91. doi:10.1016/j.immuni. 2008.11.010

82. Zhan Y, Davey GM, Graham KL, Kiu H, Dudek NL, Kay TW, et al. SOCS1 negatively regulates the production of Foxp3(+) CD4(+) T cells in the thymus. Immunol Cell Biol (2009) 87(6):473-80. doi:10.1038/icb.2009.23

83. Kohlhaas S, Garden OA, Scudamore C, Turner M, Okkenhaug K, Vigorito E. Cutting edge: the Foxp 3 target miR-155 contributes to the development of regulatory T cells. J Immunol (2009) 182(5):2578-82. doi:10.4049/jimmunol.0803162

84. Chinen T, Komai K, Muto G, Morita R, Inoue N, Yoshida H, et al. Prostaglandin E2 and SOCS1 have a role in intestinal immune tolerance. Nat Commun (2011) 2:190. doi:10.1038/ncomms1181

85. Takahashi R, Nishimoto S, Muto G, Sekiya T, Tamiya T, Kimura A, et al. SOCS1 is essential for regulatory $\mathrm{T}$ cell functions by preventing loss of Foxp3 expression as well as IFN-\{gamma\} and IL-17A production. J Exp Med (2011) 208(10):2055-67. doi:10.1084/jem.20110428

86. Chang JH, Xiao Y, Hu H, Jin J, Yu J, Zhou X, et al. Ubc13 maintains the suppressive function of regulatory $\mathrm{T}$ cells and prevents their conversion into effector-like T cells. Nat Immunol (2012) 13(5):481-90. doi:10.1038/ni.2267

87. Flowers LO, Johnson HM, Mujtaba MG, Ellis MR, Haider SM, Subramaniam PS. Characterization of a peptide inhibitor of Janus kinase 2 that mimics suppressor of cytokine signaling 1 function. J Immunol (2004) 172(12):7510-8.

88. Waiboci LW, Ahmed CM, Mujtaba MG, Flowers LO, Martin JP, Haider MI, et al. Both the suppressor of cytokine signaling 1 (SOCS-1) kinase inhibitory region and SOCS-1 mimetic bind to JAK2 autophosphorylation site: implications for the development of a SOCS-1 antagonist. J Immunol (2007) 178(8):5058-68. 
89. Mujtaba MG, Flowers LO, Patel CB, Patel RA, Haider MI, Johnson HM. Treatment of mice with the suppressor of cytokine signaling-1 mimetic peptide, tyrosine kinase inhibitor peptide, prevents development of the acute form of experimental allergic encephalomyelitis and induces stable remission in the chronic relapsing/remitting form. J Immunol (2005) 175(8):5077-86.

90. Jager LD, Dabelic R, Waiboci L, Lau K, Haider MS, Ahmed CMI, et al. The kinase inhibitory region of SOCS-1 is sufficient to inhibit T helper 17 and other immune functions in experimental allergic encephalomyelitis. J Neuroimmunol (2011) 232(1-2):108-18. doi:10.1016/j.jneuroim.2010.10.018

91. Egwuagu CE, Larkin JI. Therapeutic Targeting of STAT pathways in CNS autoimmune diseases. JAKSTAT (2013) 2:e24134. doi:10.4161/jkst.24134

92. Madonna S, Scarponi C, Doti N, Carbone T, Cavani A, Scognamiglio PL, et al. Therapeutical potential of a peptide mimicking the SOCS1 kinase inhibitory region in skin immune responses. Eur J Immunol (2013) 43(7):1883-95. doi:10.1002/eji.201343370

93. Doti N, Scognamiglio PL, Madonna S, Scarponi C, Ruvo M, Perretta G, et al. New mimetic peptides of the kinase-inhibitory region (KIR) of SOCS1 through focused peptide libraries. Biochem J (2012) 443(1):231-40. doi:10.1042/ BJ20111647

94. Albanesi C, Federici M, Giustizieri ML, Scarponi C, Girolomoni G. Suppressor of cytokine signaling-1 inhibits interferon-gamma-induced activation of human keratinocytes. Ann N Y Acad Sci (2002) 973:79-82. doi:10.1111/j.1749-6632. 2002.tb04610.x

95. Federici M, Giustizieri ML, Scarponi C, Girolomoni G, Albanesi C. Impaired IFN-gamma-dependent inflammatory responses in human keratinocytes overexpressing the suppressor of cytokine signaling 1. J Immunol (2002) 169(1):434-42.
96. Evel-Kabler K, Song XT, Aldrich M, Huang XF, Chen SY. SOCS1 restricts dendritic cells' ability to break self tolerance and induce antitumor immunity by regulating IL-12 production and signaling. J Clin Invest (2006) 116(1):90-100. doi:10.1172/JCI26169

97. Wang Y, Wang S, Ding Y, Ye Y, Xu Y, He H, et al. A suppressor of cytokine signaling 1 antagonist enhances antigen-presenting capacity and tumor cell antigen-specific cytotoxic $\mathrm{T}$ lymphocyte responses by human monocyte-derived dendritic cells. Clin Vaccine Immunol (2013) 20(9):1449-56. doi:10.1128/CVI. 00130- 13

Conflict of Interest Statement: The authors declare that the research was conducted in the absence of any commercial or financial relationships that could be construed as a potential conflict of interest.

Received: 24 September 2013; accepted: 04 December 2013; published online: 18 December 2013.

Citation: Larkin J III, Ahmed CM, Wilson TD and Johnson HM (2013) Regulation of interferon gamma signaling by suppressors of cytokine signaling and regulatory $T$ cells. Front. Immunol. 4:469. doi: 10.3389/fimmu.2013.00469

This article was submitted to Immunotherapies and Vaccines, a section of the journal Frontiers in Immunology.

Copyright (C) 2013 Larkin III, Ahmed, Wilson and Johnson. This is an open-access article distributed under the terms of the Creative Commons Attribution License (CC $B Y)$. The use, distribution or reproduction in other forums is permitted, provided the original author(s) or licensor are credited and that the original publication in this journal is cited, in accordance with accepted academic practice. No use, distribution or reproduction is permitted which does not comply with these terms. 